\title{
THERMO-MECHANICAL MODEL FOR THE MATERIAL NONLINEAR ANALYSIS OF CEMENT BASED MATERIALS
}

\author{
A. VENTURA-GOUVEIA ${ }^{*}$, JOAQUIM A.O. BARROS ${ }^{+}$, ÁLVARO F.M. AZEVEDO ${ }^{\dagger}$ \\ * Polytechnic Institute of Viseu \\ ISISE, School of Technology and Management of Viseu, Viseu, Portugal \\ e-mail: ventura@estgv.ipv.pt \\ ${ }^{+}$University of Minho \\ ISISE, School of Engineering of the University of Minho, Guimarães, Portugal \\ e-mail: barros@ civil.uminho.pt \\ ${ }^{\dagger}$ University of Porto \\ Faculty of Engineering of the University of Porto, Porto, Portugal \\ e-mail: alvaro@fe.up.pt
}

Key words: Finite element method, Thermal analysis, Early-age heat development, Smeared crack model

\begin{abstract}
Since most advanced cement based materials have relatively high binder content, the risk of cracking at an early age should be evaluated using models that can estimate the heat generated by the hydration of pozolanic components and the induced stress fields. For this purpose, a general thermal model was developed, in order to perform steady state thermal analysis, transient linear thermal analysis and nonlinear thermal analysis. The heat development due to the hydration process during the concrete hardening phase is coupled with the thermal model, leading to a numerical approach that is capable of simulating the behavior of concrete structures since its early ages. This thermal model is integrated into a mechanical model that can simulate the crack initiation and propagation in structures discretized with solid finite elements. The mechanical model is a 3D multi-directional smeared crack model with the capability of simulating the behavior of structures failing in flexure, shear or punching. The thermo-mechanical model is presented and its performance and accuracy are assessed by simulating a case study available in the literature.
\end{abstract}

\section{INTRODUCTION}

In this work a general thermal model to simulate the heat transfer in structures built with materials whose mechanical behavior can be considered to be linear or nonlinear is presented. The heat development due to the hydration process during the concrete hardening phase and its inclusion in the heat transfer model is also treated. This thermal model is integrated into a mechanical model that can simulate the crack initiation and propagation in structures discretized with solid finite elements. The predictive performance of the developed thermal-mechanical model [1] is assessed by simulating a case study available in the literature. The model is implemented in the FEMIX computer code [2].

\section{THERMAL MODEL}

Heat transfer can be defined as the energy transferred between material bodies due to a temperature difference [3-5]. The heat flows from hot to cold mediums until an equilibrium state is reached [6], being the process of heat transfer divided into three modes: conduction, convection and radiation. 


\subsection{Heat conduction equation}

The equation for the case of three dimensional (3D) heat conduction analysis is directly derived by applying the principle of conservation of energy to an infinitesimal control volume of a 3D body, as represented in Figure 1 [1].

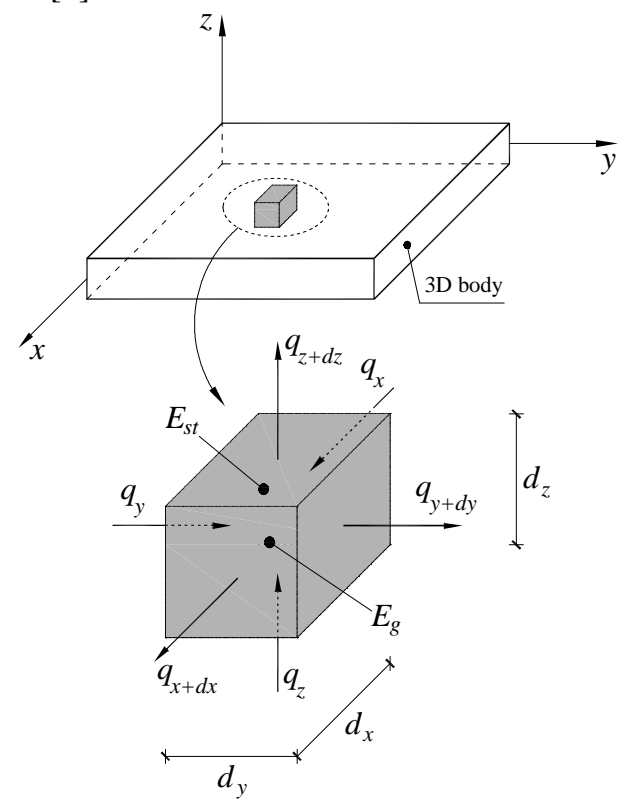

Figure 1: Infinitesimal control volume of a 3D body.

The general 3D heat conduction equation in Cartesian coordinates can be presented as follows

$$
\begin{aligned}
& \frac{\partial}{\partial x}\left(k_{x} \frac{\partial T}{\partial x}\right)+\frac{\partial}{\partial y}\left(k_{y} \frac{\partial T}{\partial y}\right)+\frac{\partial}{\partial z}\left(k_{z} \frac{\partial T}{\partial z}\right) \\
& +\dot{Q}=\rho c \frac{\partial T}{\partial t}
\end{aligned}
$$

For the case of isotropic materials, the thermal conductivity is the same in all directions, i.e., $k_{x}=k_{y}=k_{z}=k . \dot{Q}$ is the internal heat generation rate per unit volume of the infinitesimal control volume, $\rho$ is the mass per unit volume and $c$ is the specific heat of the material.

To obtain the temperature distribution in a body, the heat conduction equation must be solved considering appropriate boundary conditions, such as: prescribed temperature in the boundary; constant heat flux in the boundary; insulated or adiabatic boundary; and, convection condition on the boundary surface. The radiation heat transfer can be taken into account by substituting the convection heat transfer coefficient with an appropriate convection-radiation heat transfer coefficient, $h_{c r}$, [6-7].

For the case of time dependent temperature phenomena, the initial conditions must also be known.

\subsection{Finite element method applied to heat transfer}

The application of the method of weighted residuals to the heat conduction equation (1) yields

$$
\begin{aligned}
& \int_{V} w\left[\frac{\partial}{\partial x}\left(k_{x} \frac{\partial T}{\partial x}\right)+\frac{\partial}{\partial y}\left(k_{y} \frac{\partial T}{\partial y}\right)+\frac{\partial}{\partial z}\left(k_{z} \frac{\partial T}{\partial z}\right)\right] d V \\
& +\int_{V} w \dot{Q} d V-\int_{V} w \rho c \frac{\partial T}{\partial t} d V=0
\end{aligned}
$$

where $w$ is the weight function $w(x, y, x)$.

Integrating by parts the first term of equation (2), using the Green-Gauss theorem [8] and introducing the boundary conditions, results in

$$
\begin{aligned}
& \int_{V}\left[\frac{\partial w}{\partial x} k_{x} \frac{\partial T}{\partial x}+\frac{\partial w}{\partial y} k_{y} \frac{\partial T}{\partial y}+\frac{\partial w}{\partial z} k_{z} \frac{\partial T}{\partial z}\right] d V \\
& +\int_{S_{c}} w h_{c} T d S_{c}+\int_{V} w \rho c \frac{\partial T}{\partial t} d V \\
& =\int_{V} w \dot{Q} d V-\int_{S_{T}} w\left(q_{T}\right) d S_{T}- \\
& \int_{S_{q}} w(\bar{q}) d S_{q}+\int_{S_{c}} w h_{c} T_{\infty} d S_{c}
\end{aligned}
$$

In this equation $q_{T}$ is the unknown heat flux at the boundary where the temperature is prescribed, $\bar{q}$ is the imposed boundary heat flux (when $\bar{q}=0$ an insulated or adiabatic boundary is assumed), and $h_{c}\left(T-T_{\infty}\right)$ is the boundary convection heat flux (by substituting $h_{c}$ with $h_{c r}$, convection-radiation heat transfer can be taken into account).

The first integral of equation (3) can be written as

$$
\int_{V}(\nabla w)^{T} \underline{D} \nabla T d V
$$


where

$$
\underline{D}=\left[\begin{array}{ccc}
k_{x} & 0 & 0 \\
0 & k_{y} & 0 \\
0 & 0 & k_{z}
\end{array}\right]
$$

The temperatures can be approximated using shape functions as follows

$$
T=T(x, y, z, t)=\sum_{i=1}^{n} N_{i}(x, y, z) T_{i}(t)
$$

where $n$ is the number of nodes of the finite element, $N_{i}$ is the shape function of element node $i$ and $T_{i}$ is the temperature of element node $i$. In a transient analysis this temperature field is a function of time.

In matrix form, equation (6) can be written as

$$
T=\underline{N} \underline{T}^{e}
$$

being

$$
\underline{N}=\left[\begin{array}{llll}
N_{1} & N_{2} & \ldots & N_{n}
\end{array}\right]
$$

and

$$
\underline{T}^{e}=\left[\begin{array}{llll}
T_{1} & T_{2} & \ldots & T_{n}
\end{array}\right]^{T}
$$

By using the Galerkin method, the weight functions, $w$, are chosen to coincide with the functions that define the unknown variables (temperatures). In the present case these functions are the shape functions, $N$. Thus, equation (3) can be written for a specific finite element, considering (7) and (4), as

$$
\begin{aligned}
& \int_{V}(\nabla \underline{N})^{T} \underline{D} \nabla \underline{N}^{e} d V+\int_{S_{c}} \underline{N}^{T} h_{c} \underline{N} \underline{T}^{e} d S_{c} \\
& +\int_{V} \underline{N}^{T} \rho c \frac{\partial\left(\underline{N} \underline{T}^{e}\right)}{\partial t} d V= \\
& \int_{V} \underline{N}^{T} \dot{Q} d V-\int_{S_{T}} \underline{N}^{T}\left(q_{T}\right) d S_{T}- \\
& \int_{S_{q}} \underline{N}^{T}(\bar{q}) d S_{q}+\int_{S_{c}} \underline{N}^{T} h_{c} T_{\infty} d S_{c}
\end{aligned}
$$

or

$$
\left(\underline{K}_{c}^{e}+\underline{K}_{c o n v}^{e}\right) \underline{T}^{e}+\underline{K}_{t}^{e} \underline{\dot{T}}^{e}=\underline{F}^{e}
$$

where $\underline{K}_{c}^{e}$ is the element conduction matrix defined by

$$
\begin{aligned}
\underline{K}_{c}^{e} & =\int_{V}(\nabla \underline{N})^{T} \underline{D} \nabla \underline{N} d V \\
& =\int_{V} \underline{B}^{T} \underline{D} \underline{B} d V
\end{aligned}
$$

being

$$
\underline{B}=\left[\begin{array}{cccc}
\frac{\partial N_{1}}{\partial x} & \frac{\partial N_{2}}{\partial x} & \ldots & \frac{\partial N_{n}}{\partial x} \\
\frac{\partial N_{1}}{\partial y} & \frac{\partial N_{2}}{\partial y} & \ldots & \frac{\partial N_{n}}{\partial y} \\
\frac{\partial N_{1}}{\partial z} & \frac{\partial N_{2}}{\partial z} & \ldots & \frac{\partial N_{n}}{\partial z}
\end{array}\right]
$$

$\underline{K}_{c o n v}^{e}$ is the element convection matrix

$$
\underline{K}_{c o n v}^{e}=\int_{S_{c}} h_{c} \underline{N}^{T} \underline{N} d S_{c}
$$

and $\underline{K}_{t}^{e}$ is the element transient matrix

$$
\underline{K}_{t}^{e}=\int_{V} \rho c \underline{N}^{T} \underline{N} d V
$$

The vector $\underline{F}^{e}$ can be divided into

$$
\underline{F}^{e}=\underline{F}_{L}^{e}+\underline{F}_{q_{T}}^{e}
$$

where $\underline{F}_{L}^{e}$ is defined by

$$
\underline{F}_{L}^{e}=\underline{F}_{\dot{Q}}^{e}+\underline{F}_{\bar{q}}^{e}+\underline{F}_{c}^{e}
$$

being $\underline{F}_{\dot{Q}}^{e}$ the vector corresponding to the element internal heat generation,

$$
\underline{F}_{\dot{Q}}^{e}=\int_{V} \underline{N}^{T} \dot{Q} d V
$$

$\underline{F}_{\bar{q}}^{e}$ is the vector corresponding to the boundary where the heat flux is imposed,

$$
F_{\bar{q}}^{e}=-\int_{S_{q}} \underline{N}^{T}(\bar{q}) d S_{q}
$$

and $\underline{F}_{c}^{e}$ is the vector containing the values corresponding to the convection (or convection-radiation) boundary

$$
\underline{F}_{c}^{e}=\int_{S_{c}} \underline{N}^{T} h_{c} T_{\infty} d S_{c}
$$

In equation (16) $\underline{F}_{q_{T}}^{e}$ is the vector corresponding to the heat flux where the temperature is prescribed,

$$
\underline{F}_{q_{T}}^{e}=-\int_{S_{T}} \underline{N}^{T}\left(q_{T}\right) d S_{T}
$$


By considering a domain discretized into several finite elements, equation (11) is written in a global form as

$$
\left(\underline{K}_{c}+\underline{K}_{c o n v}\right) \underline{T}+\underline{K}_{t} \underline{\dot{T}}=\underline{F}
$$

In this equation the matrices and vectors take into account the contribution of each finite element of the domain.

For the case of a steady-state linear analysis equation (22) becomes

$$
\left(\underline{K}_{c}+\underline{K}_{c o n v}\right) \underline{T}=\underline{F}
$$

\subsection{Transient linear analysis}

Figure 2 represents the temperature variation with time for a one dimensional problem. In the incremental time step, $\Delta t$, a linear variation of the temperature is assumed. Thus, the derivative of temperature is approximated with

$$
\dot{T}_{n}=\frac{\partial T_{n}}{\partial t} \approx \frac{T_{n+1}-T_{n}}{\Delta t}
$$

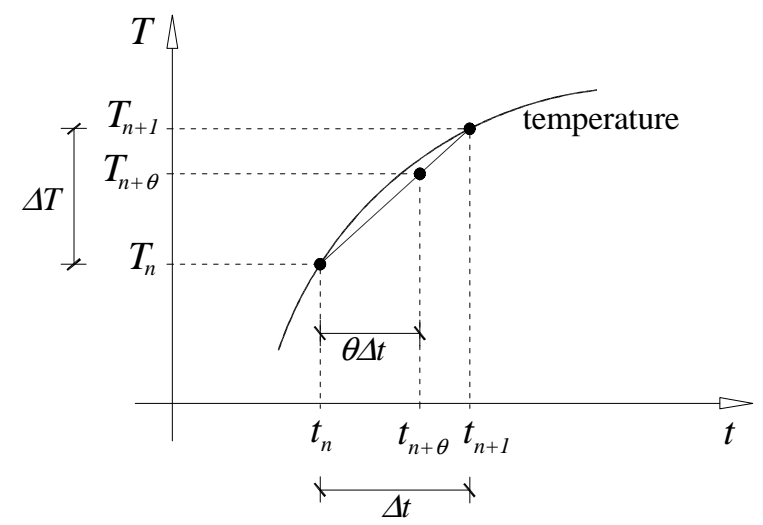

Figure 2: Time-discretization for one dimensional problems.

Considering a multi-dimensional problem, the temperature at the time $t_{n+\theta}$ is calculated with

$$
\begin{aligned}
\underline{T}_{n+\theta} & =\underline{T}_{n}+\theta \Delta t\left(\frac{\underline{T}_{n+1}-\underline{T}_{n}}{\Delta t}\right) \\
& =\theta \underline{T}_{n+1}+(1-\theta) \underline{T}_{n}
\end{aligned}
$$

and its derivative with (see Figure 2)

$$
\dot{\underline{T}}_{n+\theta}=\frac{\underline{T}_{n+\theta}-\underline{T}_{n}}{\theta \Delta t}=\frac{\underline{T}_{n+1}-\underline{T}_{n}}{\Delta t}
$$

Writing equation (22) for the time $t_{n+\theta}$ results in

$$
\left(\underline{K}_{c}+\underline{K}_{c o n v}\right) \underline{T}_{n+\theta}+\underline{K}_{t} \underline{\dot{T}}_{n+\theta}=\underline{F}_{n+\theta}
$$

and substituting (25) and (26) yields

$$
\begin{aligned}
& \left(\underline{K}_{c}+\underline{K}_{c o n v}\right)\left[\theta \underline{T}_{n+1}+(1-\theta) \underline{T}_{n}\right]+ \\
& \underline{K}_{t}\left(\frac{\underline{T}_{n+1}-\underline{T}_{n}}{\Delta t}\right)=\underline{F}_{n+\theta}
\end{aligned}
$$

Considering for vector $\underline{F}_{n+\theta}$ the same type of approximation that is adopted for the temperature, equation (28) can be written as

$$
\begin{aligned}
& {\left[\underline{K}_{t}+\theta \Delta t\left(\underline{K}_{c}+\underline{K}_{c o n v}\right)\right] \underline{T}_{n+1} } \\
= & {\left[\underline{K}_{t}-(1-\theta) \Delta t\left(\underline{K}_{c}+\underline{K}_{c o n v}\right)\right] \underline{T}_{n}+} \\
& \Delta t\left[\theta \underline{F}_{n+1}+(1-\theta) \underline{F}_{n}\right]
\end{aligned}
$$

By adopting different values for $\theta$ several time-stepping schemes can be obtained, such as: Forward-Euler $(\theta=0)$; Backward-Euler $(\theta=1)$; Crank-Nicolson $\left(\theta=\frac{1}{2}\right) ;$ Galerkin $\left(\theta=\frac{2}{3}\right)[4,9]$.

\subsection{Transient nonlinear analysis}

In the presence of early age heat development, the heat generation rate of cement based materials can be obtained with the mathematical formulation proposed by Reinhardt et al. [10] and based on the Arrhenius type relation, being defined by the following equation [7].

$$
\dot{Q}=f\left(\alpha_{T}\right) A_{T} e^{-\frac{E_{a}}{R(273.15+T)}}
$$

In this equation $\dot{Q}$ is the heat generation rate to be introduced in equation (18), $f\left(\alpha_{T}\right)$ is the normalized heat generation rate directly obtained through experiments [7,11-12], $A_{T}$ is a rate constant, $E_{a}\left(\mathrm{Jmol}^{-1}\right)$ is the apparent activation energy that depends on the type of cement, $R$ is the universal gas constant $\left(8.314 \mathrm{Jmol}^{-1} \mathrm{~K}^{-1}\right)$, and $T$ is the temperature in ${ }^{\circ} \mathrm{C}$. In this case the second member of 
equation (29) depends on the temperature and, for that reason, an iterative process is required at each time step to solve the nonlinear system of equations. The Newton-Raphson method is used for this iterative process.

For the current time step $n+1$, the equation of the unbalanced heat fluxes can be defined by [1]

$$
\underline{\Psi}\left(\underline{T}_{n+1}\right)=\underline{F}_{n+1}-\underline{E}_{n+1} \underline{T}_{n+1}
$$

For the current time step $n+1$, it is intended that the vector $\underline{\Psi}\left(\underline{T}_{n+1}\right)$ is null, i.e.,

$$
\underline{\Psi}\left(\underline{T}_{n+1}\right)=\underline{0}
$$

Equation (32) can be solved by applying the Newton-Raphson method. Considering the first two terms of the Taylor series expansion, equation (32) can be approximated as

$$
\underline{\Psi}\left(\underline{T}_{n+1}^{q}\right) \approx \underline{\Psi}\left(\underline{T}_{n+1}^{q-1}\right)+\left(\frac{\partial \underline{\Psi}}{\partial \underline{T}}\right)_{n+1}^{q-1} \delta \underline{T}_{n+1}^{q}=\underline{0}
$$

where the superscript $q$ is the iteration counter. In equation (33)

$$
\left(\frac{\partial \underline{\Psi}}{\partial \underline{T}}\right)_{n+1}^{q-1}=-\left(\frac{\partial(\underline{\bar{F}}-\underline{E} \underline{T})}{\partial \underline{T}}\right)_{n+1}^{q-1}=-\left(\underline{E}_{T}\right)_{n+1}^{q-1}
$$

is the Jacobian matrix. For simplification, the term $\partial \underline{F}_{n+1}^{q-1} / \partial \underline{T}_{n+1}^{q-1}$ is dropped in the present formulation, being the Jacobian matrix equal to the effective tangential matrix, $\underline{E}_{T}$ of the $q-1$ iteration of the current time step, $n+1$. Substituting (34) into (33) yields

$$
\left(\underline{E}_{T}\right)_{n+1}^{q-1} \delta \underline{T}_{n+1}^{q}=\underline{\Psi}\left(\underline{T}_{n+1}^{q-1}\right)
$$

An iterative procedure is executed up to the solution of equation (32), and in each iteration the vector of the temperatures is updated as follows

$$
\underline{T}_{n+1}^{q}=T_{n+1}^{q-1}+\delta \underline{T}_{n+1}^{q}=\underline{T}_{n}+\Delta \underline{T}_{n+1}^{q}
$$

with

$$
\Delta \underline{T}_{n+1}^{q}=\sum_{i=1}^{q} \delta \underline{T}_{n+1}^{i}=\Delta \underline{T}_{n+1}^{q-1}+\delta \underline{T}_{n+1}^{q}
$$

being $\quad \underline{T}_{n+1}^{0}=\underline{T}_{n} \quad$ and $\quad \Delta \underline{T}_{n+1}^{0}=\underline{0} \quad$ at the beginning of the iterative process.
The normalized heat generation rate $f\left(\alpha_{T}\right)$ is obtained directly from experiments, and is a function of the degree of heat development $\alpha_{T}$. This parameter describes the relative amount of heat generation due to the cement hydration $[7,13]$

$$
\alpha_{T}=\frac{Q(t)}{Q_{\text {total }}}
$$

where $Q(t)$ is the accumulated heat generated until a certain instant $t$, and $Q_{\text {total }}$ is the final accumulated heat of the cement (or binder) hydration. An initial value for the degree of heat development $\alpha_{T, \text { init }}$ is necessary to numerically activate the nonlinear transient analysis due to early age heat development.

\section{THERMO-MECHANICAL MODEL}

The described thermal model is integrated into a mechanical model that can simulate the crack initiation and propagation in structures discretized with solid finite elements. The mechanical model is a 3D multi-directional smeared crack model with the capability of simulating the behavior of structures failing in flexure, shear or punching, and its formulation can be found elsewhere [1,14]. In this section only the relevant aspects related to the influence of the early-age heat development in the structural response are presented.

In smeared crack models the strain components of the cracked material is the addition of the strain components in the smeared cracks, $\underline{\varepsilon}^{c r}$, with the strain components in the uncracked concrete between cracks, $\underline{\varepsilon}^{c o}$

$$
\underline{\varepsilon}=\underline{\varepsilon}^{c o}+\underline{\varepsilon}^{c r}
$$

This strain decomposition is also very suitable to take into account several time dependent effects. In this case, the strain vector of the uncracked concrete can be decomposed in order to include these effects. So, the total strain can be obtained with 


$$
\begin{aligned}
\underline{\varepsilon}(t)= & \underline{\varepsilon}^{e}\left(t_{0}\right)+\underline{\varepsilon}^{c}(t)+\underline{\varepsilon}^{s}(t)+\underline{\varepsilon}^{T}(t) \\
& +\underline{\varepsilon}^{c r}(t)
\end{aligned}
$$

where $\underline{\varepsilon}^{e}, \underline{\varepsilon}^{c}, \underline{\varepsilon}^{s}$ and, $\underline{\varepsilon}^{T}$ are the elastic, creep, shrinkage and thermal strain vectors, and $\underline{\varepsilon}^{c r}$ is the crack strain vector. A nonlinear transient analysis must be performed, since the total strain is time dependent, being its components evaluated during the time.

Let us concentrate in the thermal strain $\varepsilon^{T}(t)$. This strain can be obtained from the temperature field at a certain instant, e.g., using the results of the thermal model described in section 2 and performing the following calculation

$$
\varepsilon^{T}(t)=\alpha \Delta T
$$

being $\alpha$ the coefficient of thermal expansion and $\Delta T$ the temperature variation.

The concrete mechanical properties increases significantly with time and consequently these changes must be taken into account.

The recommendations of Eurocode 2 [15] to simulate the evolution of the compressive strength, tensile strength and modulus of elasticity are the following

$$
\begin{aligned}
& f_{c m}(t)=\beta_{c c}(t) f_{c m} \\
& f_{c t m}(t)=\left[\beta_{c c}(t)\right]^{\alpha_{1}} f_{c t m} \\
& E_{c m}(t)=\left[\beta_{c c}(t)\right]^{0.3} E_{c m}
\end{aligned}
$$

where $f_{c m}, f_{c t m}$ and $E_{c m}$ are the mean compressive strength, tensile strength, and secant modulus of elasticity of concrete at an age of 28 days, respectively. $\alpha_{1}$ is a parameter whose value depends on the considered age $t$

$$
\alpha_{1}= \begin{cases}1 & \text { for } t<28 \text { days } \\ \frac{2}{3} & \text { for } t \geq 28 \text { days }\end{cases}
$$

In equation (42) $\beta_{c c}(t)$ is determined from

$$
\beta_{c c}(t)=\exp \left\{s\left[1-\left(\frac{28}{t}\right)^{1 / 2}\right]\right\}
$$

being

$$
s= \begin{cases}0.38 & \text { for cement Class } S \\ 0.25 & \text { for cement Class } N \\ 0.20 & \text { for cement Class } R\end{cases}
$$

The evolution of the mode I fracture energy is assumed to be estimated by the following relation [1]

$$
G_{f}^{I}(t)=\left[\beta_{c c}(t)\right]^{\alpha_{1}} G_{f}^{I}
$$

where $G_{f}^{I}$ is the mode I fracture energy of concrete at an age of 28 days, and $\alpha_{1}$ is a parameter that defines the evolution of $\beta_{c c}(t)$ Since more reliable information is not available, the values indicated in equation (43) are used in the present work.

If the mean temperature differs from the reference temperature, $20^{\circ} \mathrm{C}$, the concept of equivalent age is commonly used. This concept can be defined as the age at which the hydration at the reference temperature has reached the same stage $[7,16]$, and can be determined by

$$
t_{e q}=\sum_{i=1}^{n} \mathrm{e}^{-\frac{E_{a}}{R}\left(\frac{1}{273.15+T\left(\Delta t_{i}\right)}-\frac{1}{273.15+T_{\text {ref }}}\right)} \times \Delta t_{i}
$$

being $T_{\text {ref }}$ the reference temperature $\left(20^{\circ} \mathrm{C}\right)$ and $T\left(\Delta t_{i}\right)$ the temperature in ${ }^{\circ} \mathrm{C}$ during the time period $\Delta t_{i}$ in days.

\section{NUMERICAL SIMULATION}

The performance of the model is appraised by performing a thermo-mechanical analysis of a prefabricated reinforced concrete bridge beam with a U-shaped cross section [13], as represented schematically in Figure 3.

In the precast industry different heat curing regimes [13] are frequently used to provide an early age strength development capable of anticipating the process of demolding as much as possible. In the present numerical simulation, the beam is subjected to one of these heat curing regimes, and its consequence in the strength development and eventual crack formation is assessed. 

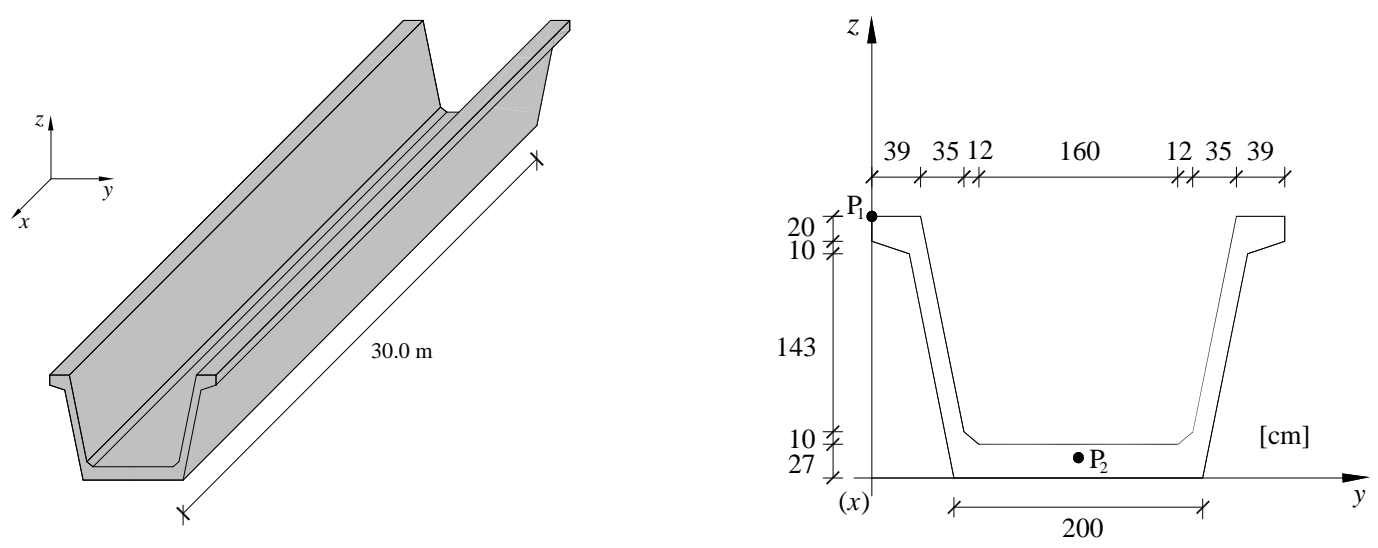

Figure 3: Geometry of the prefabricated reinforced concrete bridge beam with a U-shaped cross section.

In the carried out analysis, a beam segment of $10.0 \mathrm{~m}$ length is considered since Ferreira et al. [13] has verified that lengths greater than $10.0 \mathrm{~m}$ have no influence on the results. Due to double symmetry of the problem, only one quarter of the beam is modeled in the thermal and mechanical analysis (see Figure 6). The ordinary rebars and the prestressing cables are not taking into account since Azenha [7] has verified their marginal influence on the thermal analysis. For the mechanical analysis, the reinforcement has also a reduced influence up to the hardened phase of concrete. However, if cracking occurs the influence of the reinforcement in the cracking process can be significant, but the computing time required for the inclusion of the rebars on the simulation has supported the decision to postpone this study for a future publication.

The values that characterize the heat generation rate defined by equation (30) are dependent on the type of cement used in the concrete of the beam. The following data is used to characterize the C50/60 self-compacting concrete [13]: cement type I 52.5R $\quad\left(332 \mathrm{~kg} / \mathrm{m}^{3}\right) \quad$ with $A_{T}=1.2053 \mathrm{E}+09 \times 332, E_{a}=47.51 \mathrm{~kJ} / \mathrm{mol}$ and $Q_{\text {total }}=383.13 \times 332 \mathrm{~kJ} / \mathrm{m}^{3}$. The normalized heat generation rate $f\left(\alpha_{T}\right)$ used in the analysis is represented in Figure 4, and a value of 0.05 is considered for $\alpha_{T, \text { init }}$.

The domain is discretized with 20-noded hexahedral finite elements (see Figure 6), and a $3 \times 3 \times 3$ Gauss-Legendre integration scheme is used.

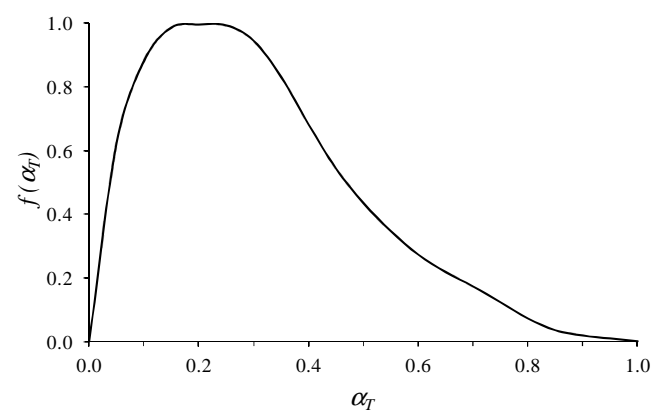

Figure 4: Normalized heat generation rate.

The conductivity of the material is constant and equal to $2.6 \mathrm{Wm}^{-1} \mathrm{~K}^{-1}$, the volumetric heat capacity, $\rho c$, is $2400.0 \mathrm{kJm}^{-3} \mathrm{~K}^{-1}$ and the initial temperature is set to $25^{\circ} \mathrm{C}$. The ambient temperature is defined by the heat curing regime imposed to the beam, and has the following development (see Figure 5): $30^{\circ} \mathrm{C}$ during $1 \mathrm{~h}$, followed by an increase of $10^{\circ} \mathrm{C} / \mathrm{h}$ until a temperature of $80^{\circ} \mathrm{C}$ is reached, then this temperature is maintained during $3 \mathrm{~h}$, followed by a decrease of $10^{\circ} \mathrm{C} / \mathrm{h}$ until the temperature of $20^{\circ} \mathrm{C}$ is attained. An equivalent heat transfer coefficient of $12.0 \mathrm{Wm}^{-2} \mathrm{~K}^{-1}$ is assigned to all exposed faces of the beam. A Backward-Euler time integration scheme is used with an incremental time step of 3600 s, being the total time of the analysis $72 \mathrm{~h}$.

Figure 5 represents the temperature evolution at two points located in the cross section of the beam coinciding with the longitudinal symmetry plane, one at the top flange, $\mathrm{P}_{1}(0.0,0.0,210.0)$, and the other at the interior of the bottom flange, $\mathrm{P}_{2}(0.0,166.0$, 18.0) (see Figure 3 and Figure 6). The 
temperature curing regime is also represented and it can be observed that the temperature at $\mathrm{P}_{1}$ and $\mathrm{P}_{2}$ points rapidly increases in the first 12 hours, and then decreases up to the ambient temperature. Temperature development in these points has similar shape format, but point $\mathrm{P}_{1}$ located at the top flange presented a higher temperature decrease rate than point $\mathrm{P}_{2}$ located at the interior of the bottom flange. Similar results were obtained by Ferreira et al. [13], and the main difference between these two studies is registered in the peak temperature observed at about 12 hours after casting. A justification can reside on eventual small differences on the location of the points and on the boundary conditions adopted in both analyses.

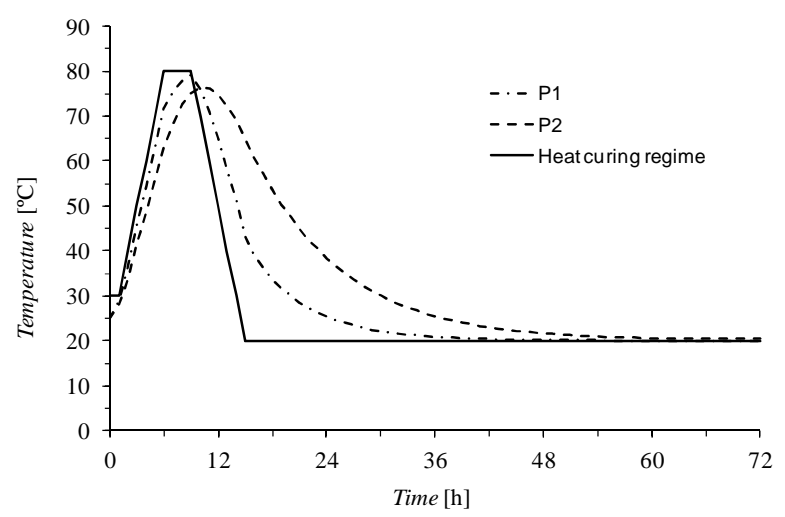

Figure 5: Heat curing regime and temperature evolution at two points of the symmetry plane of the beam.

The temperature field for different time steps of the transient analysis is represented in Figure 6. It can be observed that due to the high convection heat transfer in the external surfaces, the temperature field decreases from the center of the U-shape beam walls to the external surfaces, and tends, with time, for the ambient temperature of $20^{\circ} \mathrm{C}$.

The temperature field from the thermal transient analysis is used in the mechanical transient model described in the previous section, in order to predict the corresponding stress field. The evolution of the material properties, such as compressive strength, tensile strength and modulus of elasticity, is simulated by using equation (42). The equivalent age concept $\left(t_{e q}\right)$ obtained by equation (47) is used in equation (42), by substituting the time $t$ by $t_{e q}$. The support conditions consist in prescribed displacements in $z$ direction in all points of the bottom flange of the beam in order to simulate the vertical support provided by the formwork, and prescribed displacements to take into account the double symmetry of the beam. The material properties used in the numerical simulations are presented in Table 1. The same finite element mesh and Gauss-Legendre integration scheme used in the thermal analysis are adopted in the mechanical transient analysis.

Two numerical analysis were performed, one considering the concrete with elastic behavior and a second using the crack constitutive model. The concrete maturity is present in the numerical simulations.

Figure 7 and Figure 8 present the evolution of the normal stress in the $x$ direction and the tensile strength development for points $\mathrm{P}_{1}$ and $\mathrm{P}_{2}$, respectively. From the analysis of the curves of Figure 7 it can be stated that until an age of about $13 \mathrm{~h}$ after casting, the stress development is similar in both numerical simulations. An initial compression until an age of $9 \mathrm{~h}$ is observed, which is directly associated with the high imposed external heat curing that has conducted to an expansion of the concrete developing compression stresses in point $\mathrm{P}_{1}$, located near the surface. A quite different behavior is observed after an age of $13 \mathrm{~h}$ for the analysis that assumes an elastic behavior for the concrete and for the analysis that simulates crack formation and propagation. The analysis assuming elastic behavior does not take into account that at this age the maximum tensile strain has exceeded the strain at crack initiation, and therefore unrealistic evolution of the stress field is predicted. Using the proposed 3D multi-directional smeared crack model, the real stress development at this point is captured. It is verified that at the interception of the stress development curve and the tensile strength curve, the concrete is cracking and the stress starts decreasing immediately. 

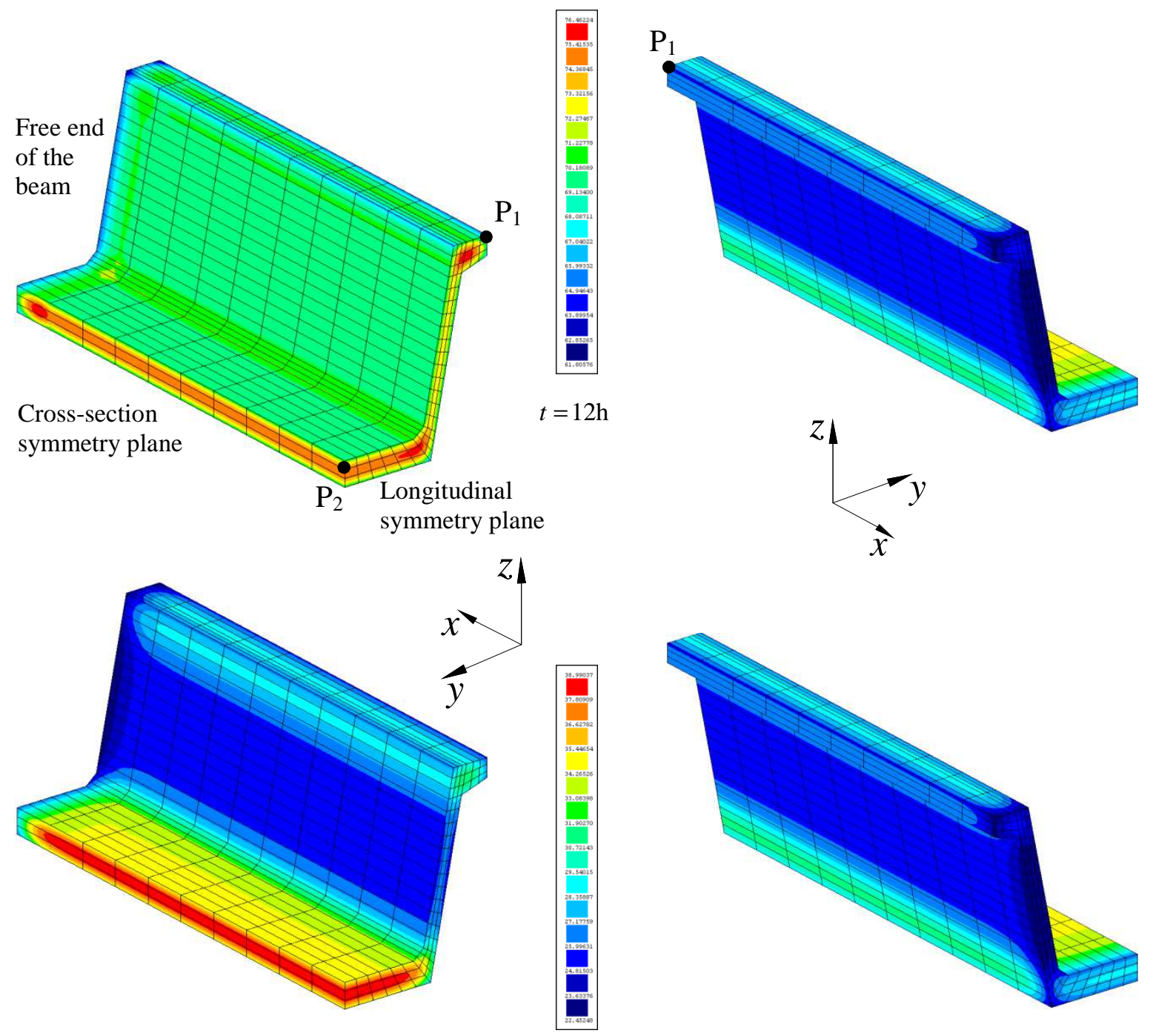

$t=24 \mathrm{~h}$
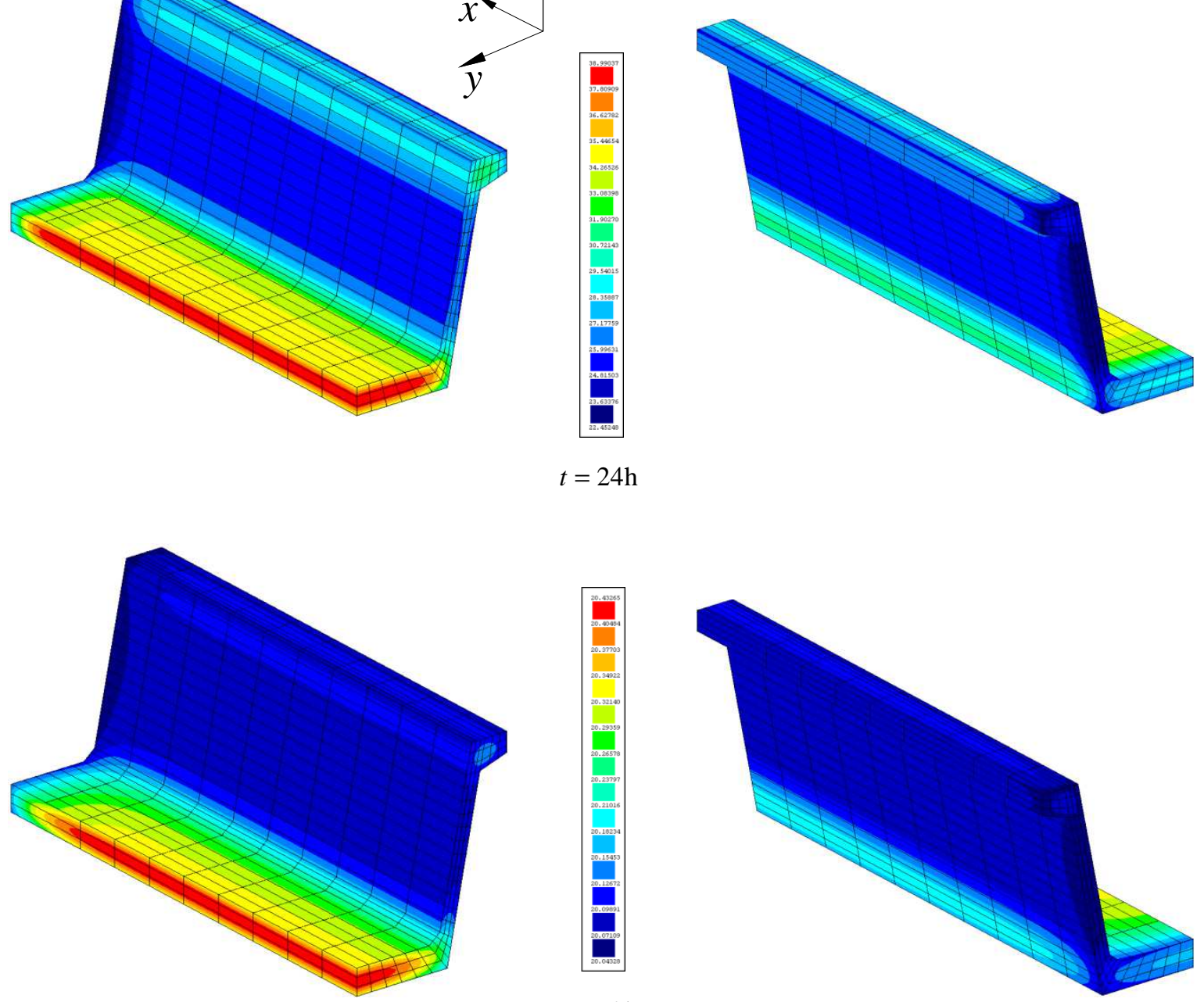

$$
t=72 \mathrm{~h}
$$

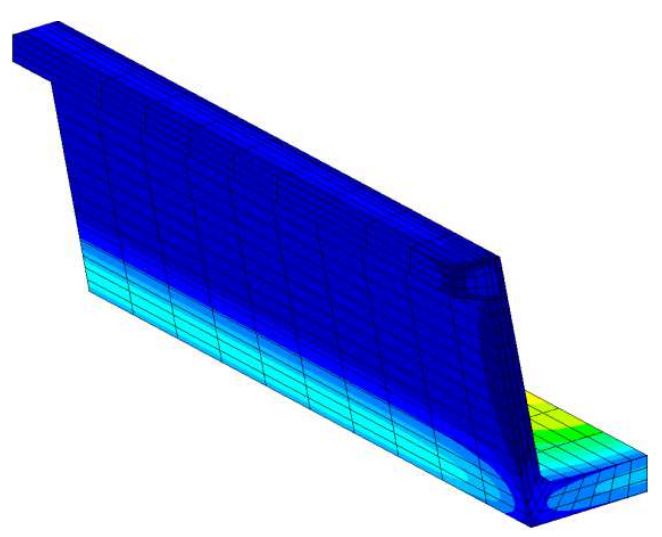

Figure 6: Finite element mesh of the structure represented in Figure 3, and temperature field for different time steps of the transient analysis. 
Table 1: Values of the parameters of the constitutive model used in the mechanical numerical simulations.

\begin{tabular}{|l|l|}
\hline \hline Poisson's ratio & $v=0.2$ \\
\hline Thermal coefficient & $\alpha=1.0 \times 10^{-5} /{ }^{\circ} \mathrm{C}$ \\
\hline Young's modulus & $E_{c m}=37.0 \mathrm{GPa}$ \\
\hline Compressive strength & $f_{c m}=58.0 \mathrm{MPa}$ \\
\hline Tension softening diagram & $\begin{array}{l}f_{c t m}=4.1 \mathrm{MPa} ; G_{f}^{I}=198.53 \times 10^{-6} \mathrm{MN} / \mathrm{m} ; \\
\xi_{1}=0.061 ; \alpha_{1}=0.15 ; \xi_{2}=0.4432 ; \alpha_{2}=0.09\end{array}$ \\
\hline $\begin{array}{l}\text { Parameter defining the mode I } \\
\text { fracture energy available to the } \\
\text { new crack }\end{array}$ & $p_{2}=0$ \\
\hline Shear retention factor & Exponential $\left(p_{1}=2\right)$ \\
\hline Crack bandwidth & Cubic root of the volume of the integration point \\
\hline Threshold angle & $\alpha_{t h}=30^{\circ}$ \\
\hline \hline
\end{tabular}

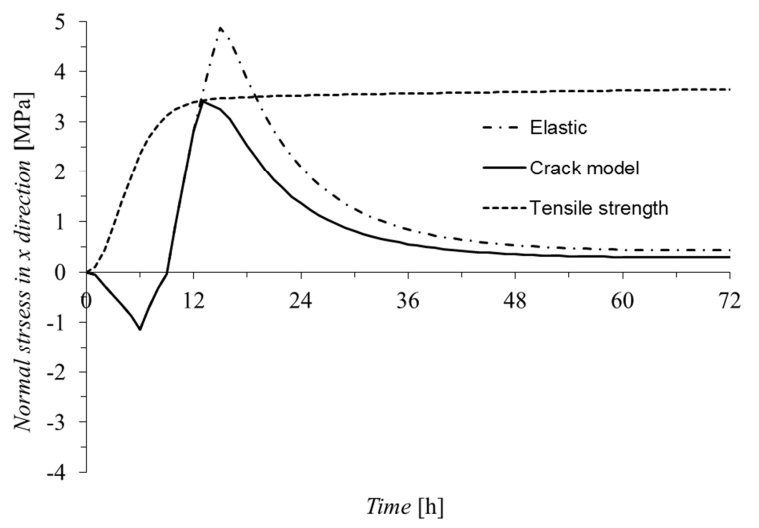

Figure 7: Evolution of the normal stress in $x$ direction and the tensile strength at point $P_{1}$.

From the analysis of the curves of Figure 8, which correspond to the stress evolution of the normal stress in $x$ direction and the tensile strength development at point $\mathrm{P}_{2}$, it can be concluded that both simulations provide similar results. Up $9 \mathrm{~h}$ point $\mathrm{P}_{2}$ is subjected to tensile stresses, and then to compressive stresses as observed in Figure 8. However, the tensile stress is always smaller than the tensile strength development, so concrete does not crack.

The crack pattern for different times of the transient mechanical analysis using the crack constitutive model is represented in Figure 9. It is observed that for an age of $14 \mathrm{~h}$, several cracks are formed, mainly in the exterior of the top flange and in the interception of the horizontal and lateral cross section walls near the free end of the beam. In consequence of temperature decreasing, these cracks tend to close, as represented in the Figure 9 for an age of $24 \mathrm{~h}$. However, for later stages the cracks reopen (see Figure 9 for $t=72 \mathrm{~h}$ ), which indicate that for the heat curing regime imposed to the beam, visible cracks can be formed, compromising the durability of the structure during its service life.

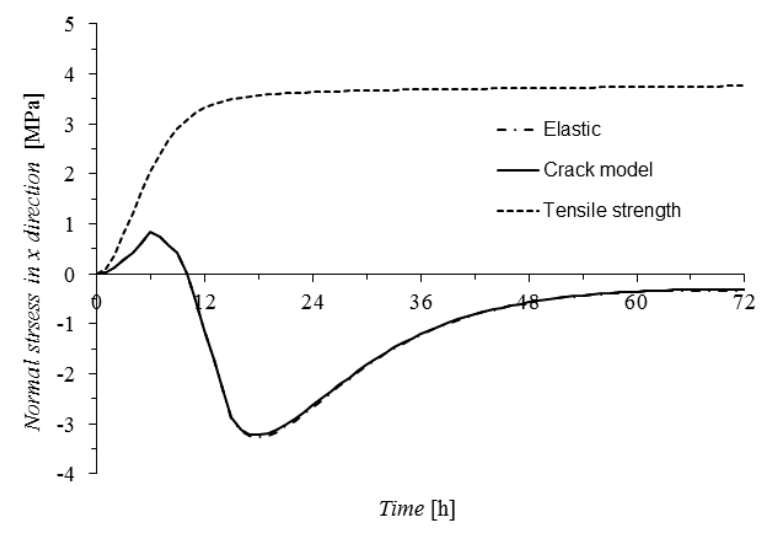

Figure 8: Evolution of the normal stress in $x$ direction and the tensile strength at point $\mathrm{P}_{2}$.

\section{CONCLUSIONS}

In the present work a thermal model with general purposes is described, in order to enable steady state thermal analyses, transient linear thermal analyses and nonlinear thermal analyses. The heat development due to the hydration process during the concrete 
hardening phase is coupled with the thermal model, leading to a tool that is capable of simulating the behavior of reinforced concrete structures since their early ages. The thermal model is integrated with the 3D multi-directional smeared crack model, and its performance is appraised using an example from the literature. A good agreement is observed.

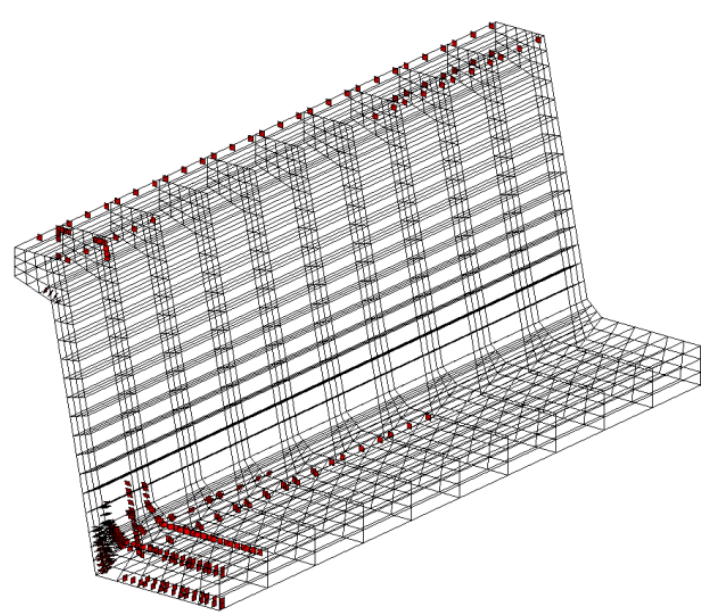

(a) $t=14 \mathrm{~h}$

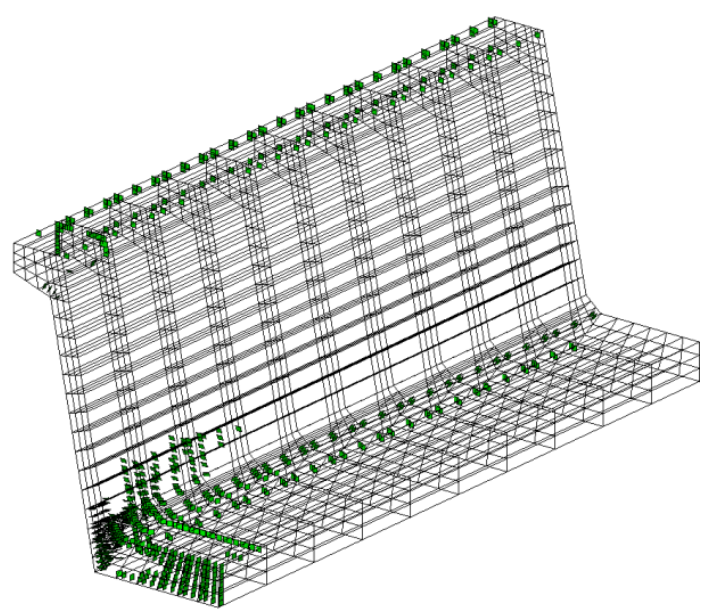

(b) $t=24 \mathrm{~h}$
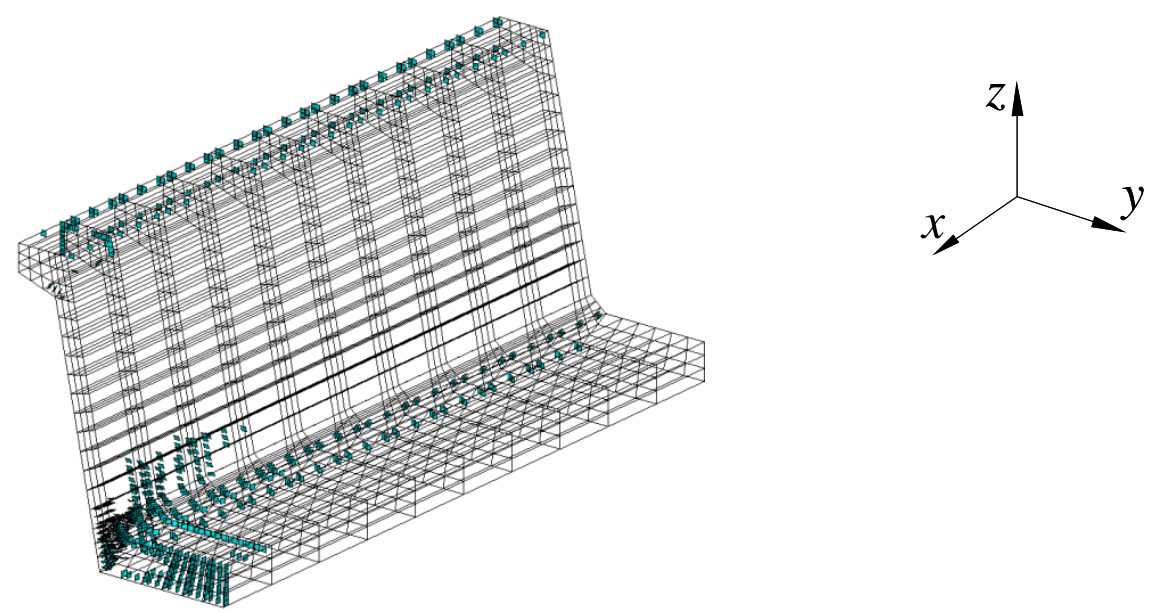

(c) $t=72 \mathrm{~h}$

Figure 9: Crack pattern for different time steps of the transient analysis: (a) opening crack status; (b) closing crack status; (c) reopen crack status.

\section{ACKNOWLEDGEMENTS}

The first author acknowledges the financial support of FCT, PhD Grant number SFRH/BD/23326/2005. The authors acknowledge the support provided by SUPERCONCRETE Marie Sklodowska-Curie Actions, Research and Innovation Staff Exchange (RISE), proposal 645704.

\section{REFERENCES}

[1] Ventura-Gouveia, A. 2011. Constitutive models for the material nonlinear analysis of concrete structures including time dependent effects, PhD Thesis, School of Engineering, University of Minho.

[2] Sena-Cruz, J.M., Barros, J.A.O., Azevedo, A.F.M. and Ventura-Gouveia, A. 2007. 
Numerical simulation of the nonlinear behavior of $R C$ beams strengthened with NSM CFRP strips, Proceedings of CMNE/CILAMCE Congress, FEUP, Porto, Portugal, 1315 June.

[3] Holman, J.P. 1986. Heat transfer, International Student Edition, McGraw Hill Book Company, sixth edition.

[4] Lewis, R.W., Nithiarasu, P. and Seetharamu, K.N. 2004. Fundamentals of the finite element method for heat and fluid flow, John Wiley \& Sons, Ltd.

[5] Incropera, F.P., DeWitt , D.P., Bergman,T.L., Lavine, A.S. 2006. Fundamentals of heat and mass transfer, Wiley, sixth edition.

[6] Silveira, A.P.C. 1993, A influência das acções térmicas no comportamento de pontes de betão armado pré esforçado (The influence of the thermal actions in the behavior of prestressed concrete bridges), PhD Thesis, IST LNEC, Lisbon [in Portuguese].

[7] Azenha, M.A.D. 2009. Numerical simulation of the structural behaviour of concrete since its early ages, $\mathrm{PhD}$ Thesis, Faculty of Engineering of the University of Porto.

[8] Ottosen, N. and Petersson, H. 1992. Introduction to the finite element method, Prentice Hall.

[9] Lewis, R.W., Morgan, K., Thomas, H.R. and Seetharamu, K.N. 1996. The finite element method in heat transfer analysis, John Wiley \& Sons, Ltd.

[10]Reihardt, H. W., Blaauwendraad, J., and Jongedijk, J. 1982. Temperature development in concrete structures taking account of state dependenty properties, Proc. Int. Conf. Concrete at Early Ages, Paris, France.

[11] de Borst, R. and van den Boogaard, A.H. 1984. Finite-element modeling of deformation and cracking in early-age concrete, Jounal of Engineering Mechanics, ASCE, 120(12), 25192534.

[12] Azenha, M.A.D., Lameiras, R.M., Sousa, C. and Barros, J.A.O. 2014. Application of air cooled pipes for reduction of early age cracking risk in a massive $R C$ wall,
Engineering Structures Journal, 62-63, 148-163.

[13]Ferreira, D., Azenha, M. and Faria R. 2008. Parametric study of the influence of heat curing methods in residual stresses of a precast concrete bridge beam, CCC2008, Torres Marques et al. (eds.), Paper published in CD - FEUP, 11 pp.

[14] Ventura-Gouveia, A., Barros, J.A.O., Azevedo, A.F.M. and Sena-Cruz, J.M. 2008. Multi-fixed smeared 3D crack model to simulate the behavior of fiber reinforced concrete structures, CCC2008, Torres Marques et al. (eds.), Paper published in CD - FEUP, 11 pp.

[15]EC2 2004. Eurocode 2 - Design of Concrete Structures-Part 1-1: General rules and rules for buildings, CEN, EN 1992-1-1, Brussels, Belgium, 225 pp.

[16]Bosnjak, D. 2000. Self-induced cracking problems in hardening concrete structures, PhD Thesis, Structural Eng. Dept., Norwegian University of Science. 